\title{
Design and Preparation of Zaltoprofen-Nicotinamide Pharmaceutical Cocrystals via Liquid Assisted Grinding Method
}

\author{
Prabhakar Panzade ${ }^{1,2 \star}$, Giridhar Shendarkar ${ }^{2}$ \\ ${ }^{1}$ Srinath College of Pharmacy, Bajaj Nagar, Waluj, Aurangabad, INDIA. \\ ${ }^{2}$ Centre for Research in Pharmaceutical Sciences, Nanded Pharmacy College, Kasturba Matruseva Kendra, Shyam Nagar, Nanded, \\ Maharashtra, INDIA.
}

\begin{abstract}
Introduction: Pharmaceutical cocrystal is an endowed approach to augment solubility and dissolution of drugs with limited aqueous solubility. Zaltoprofen is a nonsteroidal anti-inflammatory drug with prevailing solubility problem. The present study deciphers preparation of cocrystals of lipophilic drug zaltoprofen to improve the solubility and dissolution by screening various coformers. Methods: Cocrystals of zaltoprofen were prepared in 1:1 and 1:2 molar ratio of drug: coformer by liquid assisted grinding method. The crystalline phase was subjected to evaluation by melting point and solubility. The potential cocrystals were characterized by differential scanning calorimetry (DSC), infrared spectroscopy (IR), powder X-ray diffraction (PXRD) and scanning electron microscopy (SEM). Dissolution rate and stability of cocrystals was also investigated. Results: Zaltoprofen-nicotinamide (ZFN-nicotinamide) cocrystals revealed variation in melting point and solubility. Two cocrystals were obtained in 1:1 and 1:2 ratios with nicotinamide. IR spectrum distinctly showed the shifting of typical absorption bands of zaltoprofen. Crystallinity of cocrystals was clear from the PXRD pattern and noteworthy difference in $2 \theta$ value of intense peaks. DSC spectra of cocrystals revealed altered endotherms analogous to melting point. Cocrystals exhibited rapid dissolution rate and $56 \%$ increase in the extent of dissolution compared to pure drug. The cocrystals were found stable at stability conditions. SEM revealed difference in the crystal morphology. Conclusion: Hence, it can be concluded that ZFN-nicotinamide cocrystal could present an improved drug design approach to surmount dissolution and bioavailability related challenges linked with lipophilic drug zaltoprofen.
\end{abstract}

Key words: Cocrystal, Zaltoprofen, Liquid assisted grinding, Solubility, Dissolution.

\section{INTRODUCTION}

The crucial task in the development of drug product is searching appropriate solid form of an Active Pharmaceutical Ingredient (API) with desired physicochemical properties. The rational approach is a use of solid forms with greater solubility to improve dissolution and bioavailability. ${ }^{1-5}$ Amorphous solids, hydrates/solvates, polymorphs and salts have been used conventionally to improve solubility and dissolution. However, amorphous solids or metastable polymorphs of an API possess greater solubility but are thermodynamically unstable in solid state. Hence, erratic product quality and therapeutic performance may be observed. Therefore, conventional solid forms may not fulfill the need for development of successful product. ${ }^{6-11}$

Pharmaceutical cocrystals have emerged as a way of modifying solubility, dissolution, bioavailability and other physicochemical and pharmacokinetic properties of drug substances, keeping their molecular structure intact. Cocrystal is a stoichiometric multi-component system connected by non-covalent interactions containing two
Submission Date: 01-11-2018; Revision Date: 15-03-2019; Accepted Date: 18-07-2019

DOI: 10.5530/ijper.53.4s.151 Correspondence: Mr. Prabhakar Panzade, Centre for Research in Pharmaceutical Sciences, Nanded Pharmacy College, Opp. Kasturba Matruseva Kendra, Shyam Nagar- 431605 Nanded, Maharashtra, INDIA. Phone: +919921830320

E-mail: prabhakarpanzade@ gmail.com

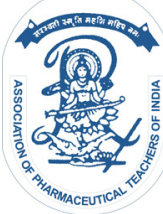

www.ijper.org 
distinct components which are solid under ambient conditions. A pharmaceutical cocrystal constitutes an API and benign food or drug grade excipient called as coformer. ${ }^{12-15}$

In the past, various attempts have been made to improve the solubility and dissolution rate of ZFN. The different methods vi\%: nanosuspension, mixed solvency, spherical crystallization were investigated to enhance the solubility of zaltoprofen. In our previous research, pharmaceutical cocrystals of zaltoprofen by neat grinding method were prepared, characterized and reported with improved solubility, dissolution rate and stability profile. ${ }^{16,17}$

Zaltoprofen is a nonsteroidal anti-inflammatory drug belongs to propionic acid class. It is used in the treatment of acute and chronic inflammation and rheumatoid arthritis. Practically, ZFN is insoluble in water and coupled with side effects like ulcerogenicity, bellyache and indigestion. ${ }^{18-20}$ Moreover, it is not possible to enhance the solubility of ZFN via salt formation due to its weakly ionisable nature. Improved bioavailability and fast onset are advantageous for analgesics. Hence there is need to prepare novel solid state forms of ZFN having modified solubility and dissolution rate. Bioavailability of ZFN a BCS class II drug is dissolution rate limited, owing to low solubility and high permeability. $^{21,22}$

Formation of cocrystals appears to be a beneficial strategy in terms of innovation of newer drugs and ease of processing as compared to other approaches to tailor solid state of a crystal.

In the present investigation, cocrystals of ZFN were prepared and characterized with the objective to enhance the solubility and dissolution rate with improved stability profile.

\section{MATERIALS AND METHODS}

\section{Materials}

Zaltoprofen was received as gift sample from ICPA laboratory Ltd. Mumbai (India). All other chemicals were purchased from the SD Fine Chemicals Mumbai (India). Double distilled water was used for the study.

\section{Preparation of cocrystal}

Liquid assisted grinding method was employed to prepare ZFN cocrystals. Drug and coformers were mixed in distinct molar ratio (1:1 and 1:2) in mortar and pestle for $45 \mathrm{~min}$ to develop cocrystals. Methanol was added drop wise in very small quantity to moisten the mixture of drug and coformer during grinding. The resultant cocrystals were dried overnight at ambient temperature, passed through 60 mesh sieve and stored in air tight container until use. The 25 coformers were screened for the preparation of cocrystals viz. salicylic acid, nicotinamide, glutaric acid, malonic acid, benzoic acid, tartaric acid, oxalic acid, citric acid, urea, succinic acid, saccharine sodium, Pluronic 68 AR, Magnesium stearate, crotonic acid, P-hydroxy benzoic acid, Caffeine, 3,5 dihydroxy benzoic acid, Piperazine citrate, Cinnamic acid, Adipic acid, Hydroquinone, Isonicotinic acid, Acetamide, Maleic acid, Ascorbic acid. ${ }^{23,24}$

\section{Evaluation of corystals}

\section{Drug content}

An accurately weighed quantity of cocrystal equivalent to $10 \mathrm{mg}$ of drug was dissolved in $10 \mathrm{ml}$ volumetric flask in phosphate buffer $\mathrm{pH}$ 6.8. The solution was filtered through whatmann filter paper (grade 41), diluted suitably and absorbance of the solution was recorded at $243 \mathrm{~nm}$. (Shimadzu UV 1800).

\section{Determination of melting point}

Digital melting point apparatus (Labtronics Ltd) was used to determine melting point of the compounds.

\section{Saturation solubility}

Solubility was determined by adding excess quantity of pure drug and cocrystals in the $10 \mathrm{ml}$ vials containing distilled water. The vials were agitated on rotary shaker and allowed to stand for equilibration for $24 \mathrm{hr}$. After 24 $\mathrm{hr}$, samples were filtered, diluted and analyzed at $243 \mathrm{~nm}$ by UV Spectrophotometer. ${ }^{25}$

\section{IR spectroscopy}

IR spectroscopy was adopted to find the probable interaction between drug and coformers. Samples were mixed with potassium bromide and compressed into discs before scanning between $4000-400 \mathrm{~cm}_{-1}$ with resolution of $4 \mathrm{~cm}_{-1}$ by shimadzu IR Spectrophotometer.

\section{Differential scanning calorimetry}

The thermal behavior of ZFN and cocrystal was determined on Mettler Toledo DSC 822e Module. Weighed samples were loaded into aluminum pan before crimping and heated at a rate of $5^{\circ} \mathrm{C} / \mathrm{min}$, covering 0 to $300^{\circ} \mathrm{C}$ temperature range, under a nitrogen stream. The instrument was calibrated using indium and empty aluminum pan was used as a reference.

\section{Powder X-ray diffraction}

The silicon sample holders were used to get diffraction patterns of pure ZFN and cocrystal (Bruker D8 Advance Diffractometer). The instrument was equipped with a fine focus $\mathrm{X}$-ray tube and each sample was placed 
on to a goniometer head that was motorized to permit spinning of the sample during data acquisition.

\section{Scanning electron microscopy}

Particle size and surface morphology of zaltoprofen and Cocrystal was studied using a general scanning electron microscope (JEOL JSM 6360A). Powder samples were sprinkled onto double sided adhesive carbon tape on an aluminium stub. A thin coating of platinum was applied to the sample using an JSC 1600 coater prior to microscopy.

\section{In vitro dissolution study}

ZFN and its cocrystals were subjected to dissolution study by USP type II apparatus (Electrolab, Mumbai, India). Dissolution study was executed in $900 \mathrm{ml}$ of $\mathrm{pH}$ 6.8 phosphate buffer at $37 \pm 0.5^{\circ} \mathrm{C}$ and $50 \mathrm{rpm}$ for 60 min. The pure drug and cocrystal equivalent to $80 \mathrm{mg}$ of drug was used for the study. The $5 \mathrm{ml}$ of samples were withdrawn after specified time interval and analyzed by UV spectrophotometer at $243 \mathrm{~nm} \cdot{ }^{26,27}$

The dissolution profiles of ZFN and cocrystals were compared by similarity factor according to following equation

$$
f_{2}=50 \log \left\{\left[1+\frac{1}{n} \sum_{n=1}^{n}\left(R_{t}-T_{t}\right)^{2}\right]^{-0.5} * 100\right\}
$$

Where $\mathrm{f}_{2}$ is similarity factor, $\mathrm{n}$ is the number of observations, $\mathrm{R}_{\mathrm{t}}$ is the average percentage drug dissolved from reference formulation and $\mathrm{T}_{\mathrm{t}}$ is the average percentage drug dissolved from test formulation. An $\mathrm{f}_{2}$ value above 50 indicates similarity in two profiles. It lies between 0 and 100 .

In addition, the dissolution profiles were statistically analyzed by Dunnet test. Results were considered significant at $P<0.05$.

\section{Micromeritic studies}

Flow properties of an API may be influenced by particle size, shape, size distribution, surface texture, moisture content and other properties. Hence, parameters such as tapped density, bulk density, angle of repose, Carr's index and Hausner's ratio that could give information regarding flow of prepared cocrystals were evaluated. ${ }^{28}$

\section{Stability study}

Stability study of selected cocrystals was performed at room temperature and $40^{\circ} \mathrm{C} \pm 20^{\circ} \mathrm{C}$ with $75 \% \pm 5 \% \mathrm{RH}$ for 3 months. The sample of $1 \mathrm{gm}$ was placed in epindron tube in stability chamber throughout the stability duration and analyzed after 30 days, 60 days and 90 days interval. The different traits were examined to assess the stability viz. drug content, melting point, solubility, in vitro drug release etc. ${ }^{29}$

\section{RESULTS AND DISCUSSION}

Among various coformers studied, nicotinamide effectively interacted with ZFN to give cocrystals. All the potential cocrystals were preliminary evaluated in terms of melting point and solubility. ZFN-nicotinamide cocrystals were selected for further studies as they demonstrated promising results.

\section{Drug content}

Drug content of ZFN-nicotinamide (1:1 and 1:2) cocrystals was determined in phosphate buffer $\mathrm{pH}$ 6.8. Drug content for 1:1 and 1:2 cocrystal was obtained $99.33 \pm 1.12 \%$ and $95.87 \pm 0.96 \%$ respectively. Result indicates drug content was within acceptable limits.

\section{Melting point and saturation solubility}

Melting point and saturation solubility of various potential cocrystals was determined and presented in Table 1. Variable changes in the melting point with different coformers were observed. Melting point of ZFN-nicotinamide cocrystal was reduced which might be due to interaction between ZFN and nicotinamide or formation of new cocrystalline phase with altered physical properties. The drop in the melting point unveiled multicomponent system and designated formation of new cocrystalline phase.

ZFN-nicotinamide cocrystals exhibited notable increase in the solubility as compared to pure drug showing effective interaction between drug and coformer. However, ZFN-nicotinamide 1:1 cocrystal indicated higher solubility $(3.28 \pm 0.336 \mathrm{mg} / \mathrm{ml})$ than $1: 2$ cocrystal $(1.372 \pm 0.875 \mathrm{mg} / \mathrm{ml})$. About 149 folds and 63 folds increase in the solubility of ZFN was observed in case of ZFN-nicotinamide $1: 1$ and 1:2 cocrystals respectively. The improved solubility of cocrystals could be due to formation of cocrystalline phase with altered physical properties viz. solubility. It can be hypothesized that, interaction between oxygen atom of the drug and primary amide hydrogen of the nicotinamide might have formed the cocrystal. Similar studies were reported for cocrystals of glipizide, aceclofenac etc. ${ }^{26,30}$

Based on the results, ZFN:nicotinamide cocrystals were further subjected to evaluation and validated.

\section{Infrared analysis}

IR spectra of zaltoprofen (Figure 1) shows the presence of the characteristic peaks which were recorded at 1699 $\mathrm{cm}^{-1}$ and 1668 for stretching of carboxylic group, -C-S- 


\begin{tabular}{|c|c|c|c|c|c|}
\hline $\begin{array}{l}\text { Drug/Potential } \\
\text { cocrystal }\end{array}$ & $\begin{array}{l}\text { Melting point of } \\
\text { conformer }\left({ }^{\circ} \mathrm{C}\right)\end{array}$ & $\begin{array}{l}\text { Cocrystal } \\
\text { melting point } \\
(1: 1)\left({ }^{\circ} \mathrm{C}\right)\end{array}$ & $\begin{array}{c}{ }^{*} \text { Cocrystal solubility } \\
(\mathrm{mg} / \mathrm{ml})(1: 1)\end{array}$ & $\begin{array}{l}\text { Cocrystal } \\
\text { melting point } \\
(1: 2)\left({ }^{\circ} \mathrm{C}\right)\end{array}$ & $\begin{array}{l}{ }^{*} \text { Cocrystal solubility } \\
(\mathrm{mg} / \mathrm{ml})(1: 2)\end{array}$ \\
\hline Zaltoprofen & $133-135$ & & $0.022 \pm 0.005$ & & \\
\hline ZFN-Salicylic acid & $158-159$ & 134 & $0.045 \pm 0.013$ & 139.5 & $0.512 \pm 0.098$ \\
\hline ZFN-Nicotinamide & $122-124$ & 118.5 & $3.28 \pm 0.336$ & 112.5 & $1.372 \pm 0.875$ \\
\hline ZFN-Glutaric acid & 96 & 117.5 & $0.045 \pm 0.005$ & 114 & $0.036 \pm 0.013$ \\
\hline ZFN-Malonic acid & 130 & 114 & $0.012 \pm 0.003$ & 111 & $0.0091 \pm 0.002$ \\
\hline ZFN-Benzoic acid & 122 & 107.5 & $0.310 \pm 0.132$ & 101 & $0.414 \pm 0.099$ \\
\hline ZFN-Tartaric acid & $164-167$ & 137 & $0.202 \pm 0.082$ & 151 & $0.0091 \pm 0.067$ \\
\hline ZFN-Oxalic acid & 99 & 116 & $0.024 \pm 0.002$ & 120.5 & $0.025 \pm 0.013$ \\
\hline ZFN-Citric acid & $148-150$ & 140.5 & $0.0098 \pm 0.005$ & 138 & $0.010 \pm 0.087$ \\
\hline ZFN- Urea & 131 & 132 & $0.112 \pm 0.072$ & 130.5 & $0.219 \pm 0.068$ \\
\hline ZFN-Succinic acid & 184 & 158.5 & $0.010 \pm 0.009$ & 155 & $0.011 \pm 0.008$ \\
\hline ZFN-Sodium saccharine & $226-230$ & 143.5 & $0.247 \pm 0.087$ & 137 & $0.227 \pm 0.090$ \\
\hline ZFN-Pluronic $68 \mathrm{AR}$ & $53-54$ & - & $0.075 \pm 0.001$ & 64.5 & $0.096 \pm 0.031$ \\
\hline $\begin{array}{l}\text { ZFN-Magnesium } \\
\text { stearate }\end{array}$ & 88.5 & 97 & $0.477 \pm 0.099$ & 94 & $0.426 \pm 0.110$ \\
\hline ZFN-Crotonic acid & $74-75$ & 105 & $1.834 \pm 0.512$ & 94.5 & $0.079 \pm 0.028$ \\
\hline $\begin{array}{l}\text { ZFN-P-hydroxy benzoic } \\
\text { acid }\end{array}$ & 208 & 156 & $0.692 \pm 0.068$ & 172 & $1.041 \pm 0.473$ \\
\hline ZFN-Caffeine & 238 & 154.5 & $0.678 \pm 0.078$ & 172 & $0.546 \pm 0.120$ \\
\hline $\begin{array}{l}\text { ZFN-3,5-dihydroxy } \\
\text { benzoic acid }\end{array}$ & $236-238$ & 183 & $0.339 \pm 0.054$ & 186 & $0.297 \pm 0.098$ \\
\hline ZFN-Piperazine citrate & $183-187^{\circ} \mathrm{C}$ & 198 & $0.224 \pm 0.045$ & 199.5 & $0.184 \pm 0.065$ \\
\hline ZFN- Cinnamic acid & $132-134$ & 110 & $0.430 \pm 0.055$ & 118.5 & $0.660 \pm 0.192$ \\
\hline ZFN-Adipic acid & $151-154$ & 132 & $0.022 \pm 0.008$ & 141 & $0.015 \pm 0.008$ \\
\hline ZFN- Hydroquinone & 172.3 & 128.5 & $0.091 \pm 0.009$ & 139 & $0.111 \pm 0.067$ \\
\hline ZFN-Isonicotinic acid & 310 & 268 & $0.103 \pm 0.067$ & 271 & $0.237 \pm 0.079$ \\
\hline ZFN-Acetamide & $79-81$ & 70 & $0.025 \pm 0.004$ & 106 & $0.016 \pm 0.008$ \\
\hline ZFN- Maleic acid & 135 & 134 & $0.058 \pm 0.008$ & 124.5 & $0.088 \pm 0.029$ \\
\hline ZFN- Ascorbic acid & 190 & 163 & $0.017 \pm 0.003$ & 154 & $0.067 \pm 0.012$ \\
\hline
\end{tabular}

*Results are expressed as mean \pm standard deviation $(n=3)$

C- aromatic streching peaks observed at $939.39 \mathrm{~cm}^{-1}$, $\mathrm{OH}$ stretching in carboxylic group at $2950 \mathrm{~cm}^{-1}$ and $\mathrm{CH}_{3}$ stretching at $1330 \mathrm{~cm}^{-1}$. The IR spectrum of nicotinamide revealed an absorption band at $3145 \mathrm{~cm}^{-1}$ for $\mathrm{NH}_{2}$ stretching of primary amide, $3342 \mathrm{~cm}^{-1}$ for pyridine ring region, $\mathrm{NH}$ bending is observed at $1593 \mathrm{~cm}^{-1}$ and aromatic $C=C$ peaks observed at $1614 \mathrm{~cm}^{-1}$. These spectra are in good agreement with the published data.

The IR bands were significantly shifted in the cocrystal in comparison to pure drug and coformer indicating interaction between drug and coformer. (Table 2)

The new peak was observed in the both cocrystal spectra at $3450 \mathrm{~cm}^{-1}$ supporting the formation of cocrystal. The peak at $3450 \mathrm{~cm}^{-1}$ may be due to formation of intermolecular hydrogen bond between hydrogen of

\begin{tabular}{|c|c|}
\hline Sample & IR peaks \\
\hline Zaltoprofen & $\begin{array}{l}\text { COOH stretching-1699 and } 1668 \\
\qquad \mathrm{~cm}^{-1} \\
\text { OH stretching }-2950 \mathrm{~cm}^{-1}\end{array}$ \\
\hline Nicotinamide & $\begin{array}{c}\mathrm{NH} 2 \text { stretching primary amide } \\
3145 \mathrm{~cm}^{-1} \\
\mathrm{NH} \text { bending } 1593 \mathrm{~cm}^{-1}\end{array}$ \\
\hline $\begin{array}{l}\text { ZFN-nicotinamide } 1: 1 \\
\text { cocrystal }\end{array}$ & $\begin{array}{c}\mathrm{COOH} \text { stretching-1623 } \mathrm{cm}^{-1} \\
\mathrm{OH} \text { stretching }-2900 \mathrm{~cm}^{-1} \\
\mathrm{NH} 2 \text { stretching primary amide } \\
3200 \mathrm{~cm}^{-1} \\
\mathrm{NH} \text { bending } 1583 \mathrm{~cm}^{-1}\end{array}$ \\
\hline $\begin{array}{l}\text { ZFN-nicotinamide 1:2 } \\
\text { cocrystal }\end{array}$ & $\begin{array}{c}\mathrm{COOH} \text { stretching-1653 } \mathrm{cm}^{-1} \\
\mathrm{OH} \text { stretching }-3000 \mathrm{~cm}^{-1} \\
\mathrm{NH} 2 \text { stretching primary amide } \\
3300 \mathrm{~cm}^{-1} \\
\mathrm{NH} \text { bending } 1593 \mathrm{~cm}^{-1}\end{array}$ \\
\hline
\end{tabular}


primary amide N-H and oxygen atom in the drug. Possible structure

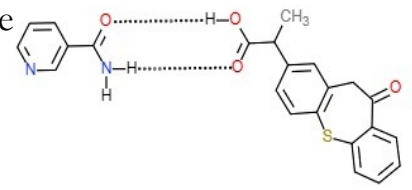

Similar changes in the IR spectrum of other drug like meloxicam, hydrochlorothiazide were reported and taken as signal of the cocrystal formation. ${ }^{31,32}$ Changes in the IR peaks of fenofibrate were used to signal the formation of cocrystal of fenofibrate with nicotinamide. The changes were attributed to possible hydrogen bonding interaction between drug and coformer. Formation of cocrystal was also authenticated in case of nevirapine cocrystal by changes in IR peak intensities. $^{33,34}$

\section{Differential scanning calorimetry}

Thermal behavior of ZFN, nicotinamide and ZFN-nicotinamide cocrystals was studied by DSC. (Figure 2) The observed melting endotherm for ZFN was obtained at $137.69^{\circ} \mathrm{C}$ whereas $129.67^{\circ} \mathrm{C}$ for nicotinamide. Similar thermal results were reported for $\mathrm{ZFN}$ and nicotinamide. In case of ZFN-nicotinamide (1:1 and 1:2) cocrystals melting point of ZFN has shifted lower and observed at $109.59^{\circ} \mathrm{C}$ and $122.66^{\circ} \mathrm{C}$ respectively. Moreover, the peak onset for ZFN was obtained at $131.52^{\circ} \mathrm{C}$ whereas ZFN-nicotinamide cocrystals (1:1 and 1:2) exhibited peak onset at $103.28^{\circ} \mathrm{C}$ and $110.61^{\circ} \mathrm{C}$ which indicates possibility of formation of the cocrystal. Hence, the present study shows formation of cocrystal as evident from the altered thermal properties which was reported as sign for cocrystal formation. Initial regions of thermogram did not contain any desolvation peak indicating no possibility of formation of solvates or hydrate. ${ }^{35}$ Cocrystals of irbesartan with chitosan were confirmed by DSC and reported. Results of DSC indicated the cocrystals were present in crystalline state and supported the formation of cocrystal. ${ }^{36}$

\section{Powder X-ray diffraction}

The fingerprint method to evaluate solid forms is PXRD. The diffractogram of ZFN and nicotinamide exhibited characteristic intense diffraction peaks at various $2 \theta$ values showing the crystalline nature. (Table 3 ) The cocrystals showed different extent of crystallinity. The PXRD pattern of the cocrystals was different from the ZFN or nicotinamide and some additional diffraction peaks were appeared which were not present in the drug or coformer (Figure 3). Hence, appearance of new diffraction peaks signals the formation of new crystalline phase. Cocrystal formation based on the PXRD pattern is well established. ${ }^{37}$ Drug-drug cocrystals of apremilast an antipsoriasis drug with nicotinamide, caffeine and salicylic acid coformers were reported. The PXRD pattern of cocrystal was different from the pure drug and used to validate formation of new cocrystal. ${ }^{38}$

\section{Scanning electron microscopy}

Surface morphology of ZFN, nicotinamide and cocrystals was studied by SEM and presented in Figure 4. ZFN showed irregular shaped crystals whereas nicotinamide exhibited rod like structure. Thread like structure of cocrytals was observed indicating the crystallinity. The substantial enhancement in crystallinity supports the formation of cocrystal. ${ }^{24}$

\section{In vitro dissolution study}

The dissolution profile of the ZFN and the prepared cocrystals is reported in Figure 5. The dissolution profile of $\mathrm{ZFN}$ indicates slow dissolution rate and total amount of drug dissolved in $60 \mathrm{~min}$ was $43.82 \%$. The calculated dissolution efficiency was only $27.4 \%$. However, cocrystals of the ZFN resulted in substantial increase in the dissolution rate. All the cocrystals exhibited complete drug release within $60 \mathrm{~min}$. The maximum amount dissolved was $99.47 \%$ for $1: 1$ cocrystal with dissolution efficiency of $86.71 \%$. Formation of cocrystal has been well established as an efficient technique for dissolution enhancement. The similarity factor test denotes the dissolution of ZFN was dissimilar to the prepared cocrystals $\left(f_{2}\right.$ value 15 and 20 for $1: 1$ and 1:2 cocrystals respectively). ${ }^{39}$

The result was compared by Dunnet test and statistically significant difference in the dissolution of cocrystals and $\mathrm{ZFN}$ was obtained $(P<0.05)$.

\section{Micromeritic characterization}

It was evident from the results that, flow properties of cocrystals were better as compared to pure ZFN. The

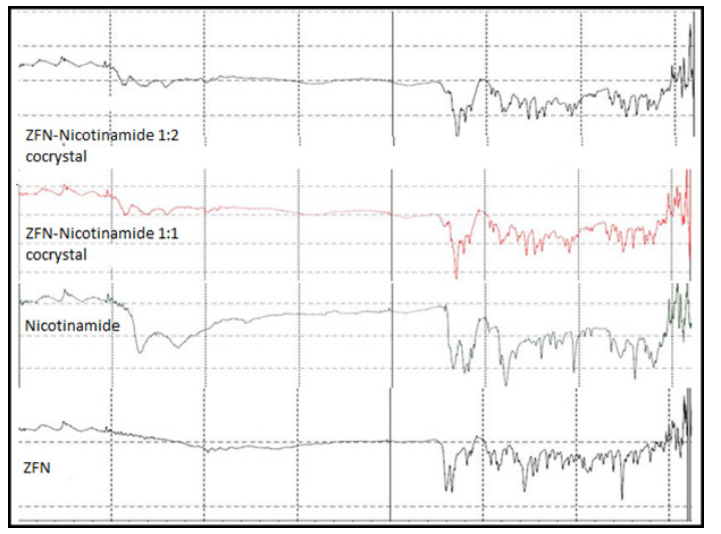

Figure 1: Overlay IR spectra of ZFN, nicotinamide and cocrystals. 


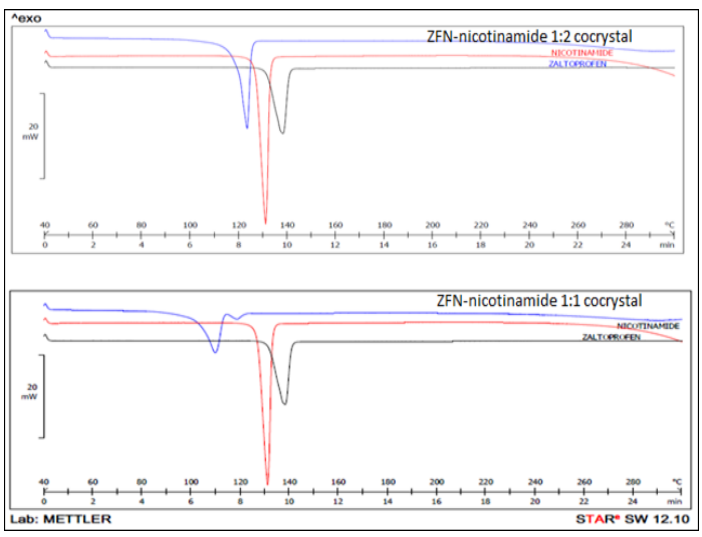

Figure 2: DSC thermograms of zaltoprofen, nicotinamide and cocrystals.
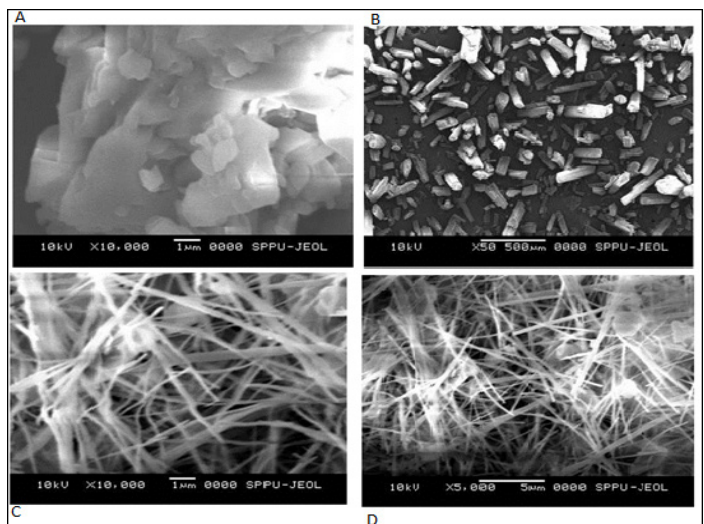

Figure 4: SEM images of Zaltoprofen (A), Nicotinamide (B), ZFN-nicotinamide 1:1 cocrystal (C) and ZFN-nicotinamide 1:2 cocrystal (D).

\begin{tabular}{|c|c|}
\hline \multicolumn{2}{|c|}{ Table 3: PXRD diffraction peaks. } \\
\hline Drug/coformer/Cocrystal & $\mathbf{2 \theta}$ values \\
\hline Zaltoprofen & $15,17.5,19,31,32.5,42$ \\
\hline Nicotinamide & $25,30,34.5,37,47.5,50.5$ \\
\hline ZFN-nicotinamide 1:1 & $11,13,19,22,27,28.5,29$, \\
Cocrystal & $44,53,57.5$ \\
\hline ZFN-nicotinamide 1:2 & $10.5,14,18,21,26.5,39$, \\
Cocrystal & $43.8,45,54.5,56$ \\
\hline
\end{tabular}

values of angle of repose, Carr's index and Hausner's ratio were greater for $\mathrm{ZFN}$ indicating the poor flow. However, the values of these parameters were lowered for cocrystals showing improved flow properties in comparison to pure ZFN (Table 4). This showed the potential of cocrystals to tailor the flow properties. ${ }^{40}$

\section{Stability study}

During storage, solubility and dissolution of cocrystals may be altered owing to change in crystallinity. Hence, stable cocrystals with greater dissolution rate are desirable. Accordingly, drug and cocrystals were subjected to stability study at room temperature and accelerated conditions for three months to assess the stability of

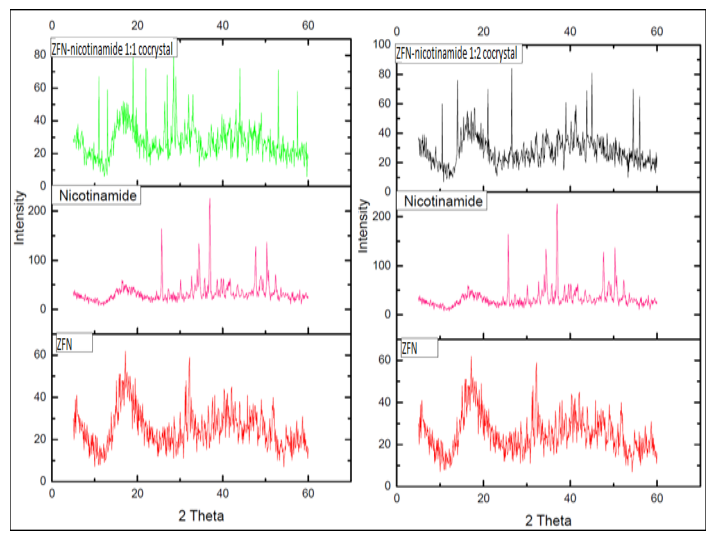

Figure 3: PXRD pattern of zaltoprofen, nicotinamide and cocrystals.

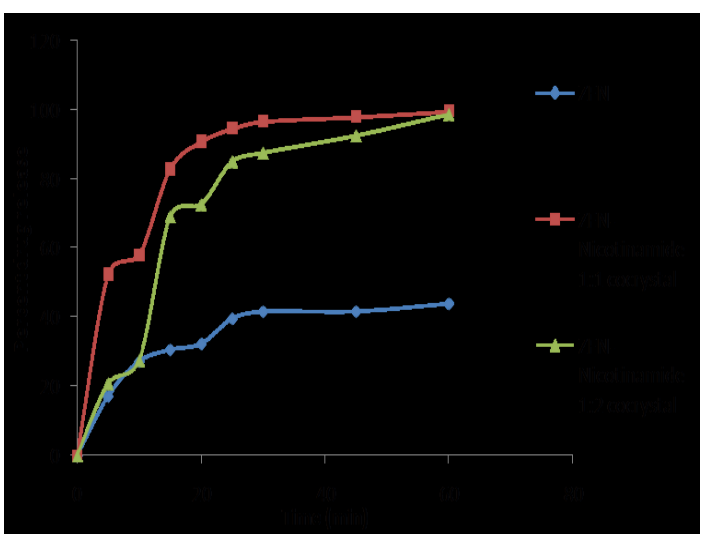

Figure 5: Dissolution study of drug and cocrystal.

cocrystals. Cocrystals were found stable at both storage conditions and no substantial change in the estimated parameters like melting point, solubility, in vitro drug release and drug content was obtained. ${ }^{41}$ (Table 5)

\section{CONCLUSION}

Pharmaceutical cocrystals of ZFN were prepared with nicotinamide by liquid assisted grinding method. Cocrystal formation was validated by DSC, IR and PXRD which jointly supported each other. SEM also revealed crystallinity supporting the formation of cocrystals. The newly prepared cocrystals exhibited higher solubility and dissolution as compared to ZFN and found stable. Cocrystals also showed potential to enhance the micromeritic characteristics. Hence, cocrystals could provide alternative drug design strategy to conquer dissolution and bioavailability pertaining problems linked with poorly soluble ZFN. However, further correlation with in vivo studies will be required.

\section{ACKNOWLEDGEMENT}

Authors are thankful to Mr. Sachin K. Jagdale for his support during the present study 


\begin{tabular}{|c|c|c|c|c|c|}
\hline Sample & $\begin{array}{l}\text { Bulk density }(\mathrm{gm} / \\
\left.\mathrm{cm}^{3}\right)\end{array}$ & $\begin{array}{c}\text { Tapped } \\
\text { density }(\mathrm{gm} / \\
\left.\mathrm{cm}^{3}\right)\end{array}$ & $\begin{array}{l}\text { Angle of repose } \\
\text { (degree) }\end{array}$ & Carr's index (\%) & $\begin{array}{l}\text { Hausner's } \\
\text { ratio }\end{array}$ \\
\hline Pure drug & $0.35 \pm 0.17$ & $0.47 \pm 0.09$ & $30.72 \pm 0.49$ & $27.84 \pm 0.88$ & $1.38 \pm 0.15$ \\
\hline $\begin{array}{c}\text { ZFN-nicotinamide } \\
1: 1 \text { cocrystal }\end{array}$ & $0.48 \pm 0.19$ & $0.57 \pm 0.23$ & $22.24 \pm 0.75$ & $14.72 \pm 0.67$ & $1.17 \pm 0.35$ \\
\hline $\begin{array}{c}\text { ZFN-nicotinamide } \\
1: 2 \text { cocrystal }\end{array}$ & $0.50 \pm 0.29$ & $0.62 \pm 0.43$ & $24.28 \pm 0.45$ & $15.12 \pm 0.62$ & $1.21 \pm 0.55$ \\
\hline
\end{tabular}

Results are expressed as mean \pm standard deviation $(n=3)$

\begin{tabular}{|c|c|c|c|c|c|c|}
\hline \multirow[t]{2}{*}{ Parameters } & \multirow[t]{2}{*}{$\begin{array}{l}\text { Zaltoprofen } \\
\text { (RT)* }\end{array}$} & \multirow[t]{2}{*}{$\begin{array}{c}\text { Zaltoprofen } \\
\text { (AT)* }\end{array}$} & \multicolumn{2}{|c|}{$\begin{array}{l}\text { Cocrystal } \\
\text { (RT)* }\end{array}$} & \multicolumn{2}{|c|}{ Cocrystal (AT)* } \\
\hline & & & $1: 1$ & $1: 2$ & $1: 1$ & $1: 2$ \\
\hline Melting point $\left({ }^{\circ} \mathrm{C}\right)$ & $131-134$ & $132-134$ & $117-118$ & $110-114$ & $116-117$ & $113-117$ \\
\hline Solubility (mg/ml) & 0.0131 & 0.01445 & 2.162 & 1.296 & 2.148 & 1.149 \\
\hline $\begin{array}{c}\text { In vitro dissolution } \\
(\%)\end{array}$ & 63.63 & 64.06 & 99.47 & 98.04 & 99.48 & 99.79 \\
\hline Drug content & - & - & 99.96 & 95.15 & 99.99 & 95.02 \\
\hline
\end{tabular}

*RT - Room temperature, AT- Accelerated temperature

\section{CONFLICT OF INTEREST}

The authors declare that there are no conflicts of interest.

\section{ABBREVIATIONS}

ZFN: Zaltoprofen, IR: Infrared spectroscopy, DSC: Differential scanning calorimetry, SEM: Scanning electron microscopy; PXRD: Powder x-ray diffraction.

\section{REFERENCES}

1. Schultheiss N, Newman A. Pharmaceutical cocrystals and their physicochemical properties. Cryst Growth Des. 2009;9(6):2950-67.

2. Miroshnyk I, Mirza S, Sandler N. Pharmaceutical co-crystals-an opportunity for drug product enhancement. Expert Opin Drug Deliv. 2009;6(4):333-41.

3. Blagden N, DeMatas M, Gavan PT, York P. Crystal engineering of active pharmaceutical ingredients to improve solubility and dissolution rates. Adv Drug Deliv Rev. 2007;59(7):617-30.

4. Gadade DD, Pekamwar SS. Pharmaceutical Cocrystals: Regulatory and strategic aspects, design and development. Adv Pharm Bull. 2016;6(4):47982.

5. Kale DP, Zode SS, Bansal AK. Challenges in Translational Development of Pharmaceutical Cocrystals. J Pharm Sci. 2017;106(2):457-70.

6. Dalpiaz A, Pavan B, Ferretti V. Can pharmaceutical co-crystals provide an opportunity to modify the biological properties of drugs?. Drug Discov Today. 2017;22(8):1134-8.

7. Bolla G, Nangia A. Pharmaceutical cocrystals: walking the talk. Chem Comm. 2016;52(54):8342-60.

8. Kuminek G, Cao F, DaRocha AB, Cardoso SG, Rodríguez-Hornedo N Cocrystals to facilitate delivery of poorly soluble compounds beyond-ruleof-5. Adv Drug Deliv Rev. 2016;101:143-66.

9. Qiao N, Li M, Schlindwein W, Malek N, Davies A, Trappitt G. Pharmaceutical cocrystals: An overview. Int J Pharm. 2011;419(1-2):1-11.
10. Shiraki K, Takata N, Takano R, Hayashi Y, Terada K. Dissolution improvement and the mechanism of the improvement from cocrystallization of poorly watersoluble compounds. Pharm Res. 2008;25(11):2581-92.

11. Shan N, Zaworotko MJ. The role of cocrystals in pharmaceutical science. Drug Discov Today. 2008;13(9-10):440-6.

12. Nanjwade VK, Manvi FV, Ali MS, Nanjwade BK, Maste MM. New trends in the co-crystallization of active pharmaceutical ingredients. J Applied Pharm Sci. 2011;8(1):1-5.

13. Good DJ, Rodríguez-Hornedo N. Solubility advantage of pharmaceutical cocrystals. Cryst Growth Des. 2009;9(5):2252-64.

14. Chow K, Tong $\mathrm{HH}$, Lum S, Chow AH. Engineering of pharmaceutical materials: An industrial perspective. J Pharm Sci. 2008;97(8):2855-77.

15. Sun CC. Cocrystallization for successful drug delivery. Expert Opin Drug Deliv. 2013;10(2):201-13.

16. Papdiwal A, Pande V, Sagar K. Design and characterization of zaltoprofen nanosuspension by precipitation method. Der Pharma Chemica. 2014;6(3):161-4.

17. Krishna EH, Gupta VR, Krishna M, Jyothi S, Dasari R. Preparation and evaluation of sodium CMC zaltoprofen spherical agglomerates for direct compression. J Pharm Res. 2013;6(1):61-7.

18. Baek J, Lim J, Kang J, Shin S, Jung S, Cho C. Enhanced transdermal drug delivery of ZFN using a novel formulation. Int J Pharm. 2013;453(2):358-62.

19. Ratnesh M, Kedar SP, Lokesh KB. Preparation, optimization and evaluation of Zaltoprofen-loaded microemulsion and microemulsion-based gel for transdermal delivery. J Liposome Res. 2016;26(4):297-306.

20. Higuchi T, Takeuchi A, Munesue S, Yamamoto N, Hayashi K, Kimura H, et al. Anti-tumor effects of a nonsteroidal anti-inflammatory drug zaltoprofen on chondrosarcoma via activating peroxisome proliferator-activated receptor gamma and suppressing matrix metalloproteinase-2 expression. Cancer Med. 2018;7(5):1944-54.

21. Raju OS, Savita DP. Gelatin-k-carrageenan polyelectrolyte complex hydrogel compositions for the design and development of extended-release pellets. Int J Polym Mater Po. 2017;66(16):812-23.

22. Raju OS, Savita DP. Fabrication and statistical optimization of starch-kcarrageenan cross-linked hydrogel composite for extended release pellets of zaltoprofen. Int J Biol Macromol. 2018;120( Part B):2324-34. 
23. Goud NR, Gangavaram S, Suresh K, Pal S, Manjunatha SG, Nambiar S, et al. Novel furosemide cocrystals and selection of high solubility drug forms. J Pharm Sci. 2012;101(2):664-80.

24. Mulye SP, Jamadar SA, Karekar PS, Pore YV, Dhawale SC. Improvement in physicochemical properties of ezetimibe using a crystal engineering technique. Powder Technol. 2012;222:131-8.

25. Sanphui P, Kumar SS, Nangia A. Pharmaceutical cocrystals of niclosamide. Cryst Growth Des. 2012;12(9):4588-99.

26. Pandey NK, Sehal HR, Garg V, Gaur T, Kumar B, Singh SK, et al. Stable Co-crystals of Glipizide with Enhanced Dissolution Profiles: Preparation and Characterization. AAPS Pharm Sci Tech. 2017;18(7):2454-65.

27. Yamashita $\mathrm{H}$, Sun $\mathrm{CC}$. Improving dissolution rate of carbamazepine-glutaric acid cocrystal through solubilization by excess coformer. Pharm Res. 2018;35(1):4.

28. Abbas N, Latif S, Afzal H, Arshad MS, Hussain A, Sadeeqa S, et al. Simultaneously Improving Mechanical, Formulation and in vivo Performance of Naproxen by Co-Crystallization. AAPS Pharm Sci Tech. 2018;19(7):324957.

29. Amaral LHD, DoCarmo FA, Amaro MI, DeSousa VP, DaSilva LC, DeAlmeida GS. Development and characterization of dapsone cocrystal prepared by scalable production methods. AAPS Pharm Sci Tech. 2018;19(6):2687-99.

30. Ganesh M, Jeon UJ, Ubaidulla U, et al. Chitosan cocrystals embedded alginate beads for enhancing the solubility and bioavailability of aceclofenac. Int J Biol Macromol. 2015;74:310-7.

31. Cheney ML, Weyna DR, Shan N, Hanna M, Wojtas L, Zaworotko MJ. Coformer selection in pharmaceutical cocrystal development: a case study of a meloxicam aspirin cocrystal that exhibits enhanced solubility and pharmacokinetics. J Pharm Sci. 2011;100(6):2172-81.

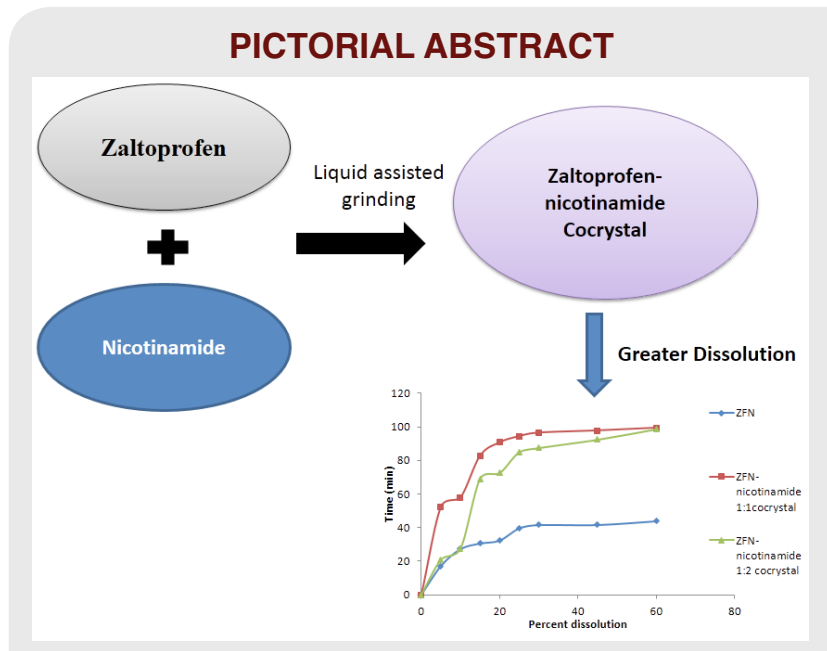

32. El-Gizawy SA, Osman MA, Arafa MF, EIMaghraby GM. Aerosil as a novel cocrystal co-former for improving the dissolution rate of hydrochlorothiazide. Int J Pharm. 2015;478(2):773-8.

33. Shete AS, Khandagale VV, Murthy SM, Vyankatrao A. Solid State Characterization and Tableting Studies of Ethanol Based Cocrystals of Fenofibrate with Nicotinamide. Ind J Pharm Edu Res. 2018;52(1):71-7.

34. Samsodien H, Bapoo M, Doms TI, Harneker Z, Louw AS. FTIR, Dissolution and Anti-viral Activity of Nevirapine Cocrystals. Pharm Anal Acta. 2017;8(9):110.

35. Patil SP, Modi SR, Bansal AK. Generation of 1: 1 carbamazepine: Nicotinamide cocrystals by spray drying. Eur J Pharm Sci. 2014;62:251-7.

36. Shete AS, Yadav AV, Murthy MS. Enhancement of Dissolution Rate of Irbesartan by Chitosan based Crystal Engineering Technique. Ind J Pharm Edu Res. 2012;46(4):323-9.

37. Shayanfar A, Jouyban A. Physicochemical characterization of a new cocrystal of ketoconazole. Powder Technol. 2014;262:242-8.

38. Feng-Yuan WAB, Zhang QI, Zaiyong Z, Xiaoyi G, Jian-Rong W, Xuefeng M. Solid-state characterization and solubility enhancement of apremilast drugdrug cocrystals. Cryst Eng Comm. 2018;39(20):5945-8.

39. Panzade P, Shendarkar G, Shaikh S, Rathi PB. Pharmaceutical Cocrystal of Piroxicam: Design, formulation and evaluation. Adv Pharm Bull. 2017;7(3):399-8

40. Yadav AV, Dabke AP, Shete AS. Crystal engineering to improve physicochemical properties of mefloquine hydrochloride. Drug Dev Ind Pharm. 2010;36(9):1036-45.

41. Sanphui $P$, Kumar SS, Nangia A. Pharmaceutical cocrystals of niclosamide. Cryst Growth Des. 2012;12(9):4588-99.

\section{About Authors}

SUMMARY
Pharmaceutical cocrystals of zaltoprofen were successfully prepared with nicotinamide coformer in 1:1 and 1:2 ratio using liquid assisted grinding method. The changes in melting point and solubility provided initial clue regarding cocrystal formation. The formation of cocrystals was further validated by alteration in IR, DSC, PXRD and SEM. The ZFN-nicotinamide cocrystals exhibited improved solubility and dissolution as compared to pure drug.

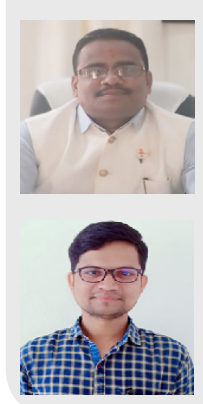

Dr. Giridhar R. Shendarkar: is Principal, Nanded Pharmacy College (Poly) and Research Superviser, CRPS, Nanded Pharmacy College, Nanded. He has 17 years of experience in academics and Research. He has published several papers in journals of high repute and has presented papers in national and international conferences. He also has some books to his credit.

Mr. Prabhakar S. Panzade: is Assistant Professor at Department of Pharmaceutics, Srinath College of Pharmacy, Aurangabad. He teaches Physical Pharmaceutics to undergraduate students and supervised several MPharm students. He has 9 years of experience in academics and engaged in research. He has published several papers in journals of high repute.

Cite this article: Panzade P, Shendarkar G. Design and Preparation of Zaltoprofen-Nicotinamide Pharmaceutical Cocrystals via Liquid Assisted Grinding Method. Indian J of Pharmaceutical Education and Research. 2019;53(4s):s563-s570. 